\title{
ANALISIS METODE IQRA DALAM PEMBACAAN FAWATIHUSSUWAR MAHASISWA FAI UHAMKA
}

\section{Fitri Liza}

Program Studi Pendidikan Agama Islam Universitas Muhammadiyah Prof. Dr. HAMKA Jakarta Email : Fitriliza70@yahoo.co.id HP 081316565632

\begin{abstract}
Learning Alquran consists of two words called "learning words" and "AlQur'an words". The word learning we are analyzing is learning in the sense of guiding and training children to read the Qur'an properly and correctly and can practice it in daily life. This type of research is a descriptive quantitative with qualitative descriptive interpretation. The place of the research was conducted at FAI UHAMKA Jalan Limau II, South Jakarta. While the research period was from October to February 2019. The population of the study was all FAI students, especially semester 1 Islamic Education Study Program. The samples used in this study were 124 first semester PAI students. Data collected includes primary data. Primary data was obtained from questionnaires in the form of google form filled by PAI students related to the Iqra Method in Faihussuwar's reading of Fai Uhamka's students. The results of this study Students still do not know and understand the verses of Muqothoat. Students still do not know and understand the subject matter. They can recite the verses of the muqothoat and fawatihussuwar correctly but they still do not know and understand that some verses of the questionnaire above are verses of muqothoat and fawatihussuwar.
\end{abstract}

Keywords : fawatihussuwar, iqra, FAI UHAMKA

\begin{abstract}
ABSTRAK
Pembelajaran Al-quran terdiri dari dua kata yakni kata 'pembelajaran' dan 'Al-quran'. Kata pembelajaran yang dianalisa adalah pembelajaran dalam arti membimbing dan melatih anak untuk membaca Al-quran dengan baik dan benar serta dapat mengamalkan dalam kehidupan seharihari. Jenis penelitian ini adalah deskriptif kuantitatif dengan interpretasi deskriptif kualitatif. Tempat dilaksanakan penelitian di FAI UHAMKA, jalan Limau II Jakarta Selatan. Sedangkan waktu penelitian dari bulan Oktober 2018 sampai dengan Februari 2019. Populasi penelitian adalah seluruh mahasiswa FAI khususnya Prodi Pendidikan Agama Islam semester satu. Sampel yang dipakai dalam penelitian ini berjumlah 124 orang mahasiswa PAI semester satu. Data yang dikumpulkan meliputi data primer. Data primer diperoleh dari kuisioner berupa google formulir yang diisi oleh mahasiswa PAI terkait Metode Iqra dalam Pembacaan Fawatihussuwar Mahasiswa FAI UHAMKA. Hasil penelitian ini menunjukkan mahasiswa masih belum mengetahui dan memahami ayatayat muqothoat. Mahasiswa masih belum mengetahui dan memahami fawatihussuwar. Mereka dapat melafalkan ayat-ayat muqothoat dan
\end{abstract}


fawatihussuwar dengan benar tetapi mereka masih belum mengetahui dan memahami bahwa beberapa ayat dari angket penelitian merupakan ayatayat muqothoat dan fawatihussuwar.

\section{Kata Kunci : fawatihussuwar, iqra, FAI UHAMKA}

\section{PENDAHULUAN}

Metode IQRA yang digunakan pada penelitian ini disusun oleh Ustadz As'ad Human yang berdomisili di Yogyakarta. Kitab IQRA tersebut terdiri dari enam jilid yang berisi tentang pembelajaran baca Quran dan satu jilid yang berisi tentang doa-doa. Dalam setiap jilid terdapat petunjuk pembelajarannya dengan maksud memudahkan setiap orang yang ingin belajar maupun yang mengajar Al-Qur'an.

Pada jurnal Al-Athfal (2016) yang berjudul 'Pembelajaran Efektif Membaca Al-quran dengan metode IQRA di Raudhatul Atfhfal' berisi tulisan bagaimana pembelajaran membaca AlQur`an untuk anak secara efektif sesuai standar membaca untuk tingkat anak-anak. Dalam jurnal tersebut, guru sebagai pengajar pada pelaksanaan pembelajarannya selalu membuat perencanaan pembelajaran dan mempersiapkan alat-alat ajar yang dibutuhkan dan disesuaikan dengan materi pelajaran Al-Qur`an yang sesuai modul. Salah satunya adalah Metode dalam pembelajaran Al-quran adalah metode Iqra`. Selain itu juga guru menyiapkan kartu kertas prestasi untuk menilai siswa. Efektifitasnya terletak pada perubahan penggunaan metode dari klasikal menjadi metode individu karena dianggap hasilnya lebih baik. Dengan metode klasikal anak yang kurang menguasai tidak bisa diketahui, namun jika menggunakan metode individu masing-masing anak dapat dikontrol kemajuannya.

Dari jurnal tersebut diperoleh informasi bahwa metode membaca Al-quran dengan metode Iqra lebih efektif dan baik untuk digunakan sebagai media belajar membaca Al-quran. Hanya saja kata-kata dalam ayat fawatihussuwar anak-anak lebih cenderung mengalami banyak kekeliruan ketika melafalkan bacaan tersebut.

IQRA ialah sebuah media pembelajaran Al-quran dari pengenalan huruf-huruf hijaiyah yang disesuaikan berdasarkan jilid 1 sampai jilid 6. Jika dilihat arti kata IQRA sendiri berarti bacalah, yang dapat dimaknai segala sesuatu yang berhubungan dengan ilmu pengetahuan harus berawal dari membaca. Begitu juga dengan IQRA yang fungsinya sebagai tahap awal untuk bisa dan lancar membaca Al-qur'an.

Metode IQRA memang sudah diakui dan dimanfaatkan banyak orang. Pemerintah sendiri juga telah menganugrahkan penghargaan kepada K.H. As'ad Humam atas hasil karyanya ini. Tahun 1991 Menteri Agama RI pada saat itu, H. Munawir Sjadzali MA menjadikan TKA/TPA 
yang didiriakn K.H. As'ad Humam di kampung Selokraman Kotagede Yogya sebagai balai litbang LPTQ Nasional, yang berfungsi sebagai Balai Latihan dan Lembaga Pengembangan Tilawatil Qur'an.

Metode IQRA terdiri dari 6 jilid dengan variasi warna cover yang memikat perhatian anak TK Al-quran. Selain itu, didalam masing-masing jilid dari buku panduan IQRA ini sudah dilengkapi dengan bagaimana cara membaca dan petunjuk mengajarkan kepada santri.

Cara belajar membaca Al-Qur'an dengan motode IQRA ini pernah dijadikan proyek oleh Departemen Agama RI sebagai upaya untuk mengembangkan minat baca terhadap kitab suci Alquran. Meski demikian, harus diakui bahwa setiap metode memiliki kelebihan dan juga kelemahannya sendiri. Oleh karena itu, perlu ada upaya konvergensi dengan memodifikasi beberapa metode guna mendapatkan metode pembelajaran yang menarik, menyenangkan, dan efektif.

Dengan penerapan metode Iqra yang pelafalannya sesuai dengan bunyi harokatnya, maka peneliti ingin mengetahui akan pemahaman mahasiswa Pendidikan Agama Islam dalam membaca ayat-ayat Muqotoat dan fawatihussuwar dalam melafalkan ayat-ayat tersebut sebagaimana di dalam metode IQRA tidak disisipkan metode pelafalan ayat-ayat fawatihussuwar. Pada kenyataannya masih banyak mahasiswa Pendidikan Agama Islam yang belum mengetahui istilah fawatihussuwar dan belum mengerti cara pelafalan ayat-ayat dari fawatihussuwar tersebut.

Untuk ayat-ayat fawatihussuwar yang familiar mahasiswa mampu melafalkan ayat tersebut dengan baik dan benar, tetapi setelah diujikan dengan contoh ayat fawatihussuwar yang lain, mahasiswa masih belum lancar dan masih melafalkan sesuai dengan metode IQRA yang biasa mereka terapkan ketika mereka belajar membaca Al-quran. Dengan landasan pemikiran tersebutlah maka peneliti melakukan analisis metode IQRA dalam pembacaan ayat fawatihussuwar.

\section{METODE}

Metode penelitian ini menggunakan metode kuantitatif deskriptif dengan menyebarkan kuisioner berupa pertanyaan huruf-huruf fawatihusuwar dan menganalisa hasil jawaban dari kuisoner yang diisi oleh responden sebanyak 124 orang mahasiswa. Populasi penelitian adalah seluruh mahasiswa FAI UHAMKA Semester I. Sampel yang dipakai dalam penelitian ini sampel jenuh berjumlah 124 mahasiswa semester I. Data yang dikumpulkan meliputi data primer. Data primer diperoleh dari hasil instrument yang diisi oleh mahasiswa FAI UHAMKA. 
Dalam pnelitian ini, langkah penelitian yang dilakukan oleh peneliti sebagai berikut :

1. Peneliti mengajukan permohonan kepada pimpinan Fakultas Agama Islam untuk dilakukan analisis metode Iqra dalam pembacaan fawatihussuwar mahasiswa FAI UHAMKA

2. Setelah mendapatkan izin dari pimpinan Fakultas Agama Islam, peneliti mengajukan surat permohonan kepada Dekan untuk menyebarkan kuisioner analisis metode Iqra dalam pembacaan fawatihussuwar kepada mahasiswa FAI UHAMKA

3. Setelah dilakukan penyebaran kuisioner, data hasil kuisioner tersebut kami olah untuk dianalisis respon sampel dengan membuat persentase seberapa paham dan bisanya mereka dalam melafadzkan ayat-ayat fawatihussuwar.

4. Setelah hasil data keluar kami lakukan interpretasi dari hasil data output Google form yang kami sebarkan ke mahasiswa FAI UHAMKA.

Untuk lebih jelaskan bisa dilihat dari desain yang digunakan dalam penelitian ini. Desain tersebut sebagai berikut:

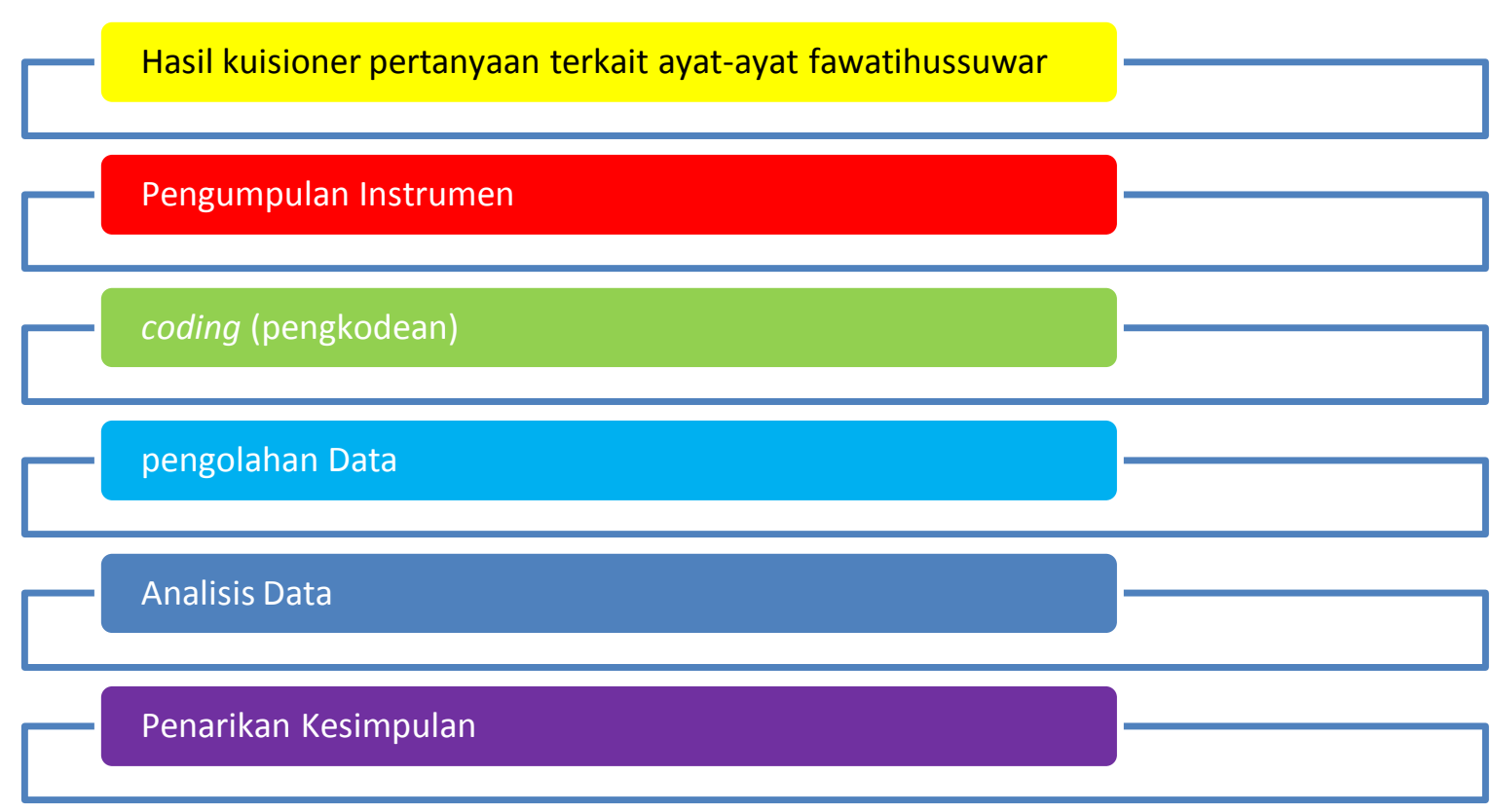

\section{ANALISA DATA}

Pada penelitian ini, peneliti menganalisis hasil questioner yang diisi oleh responden dengan mengolah data bersadarkan jawaban questioner yang diisi oleh responden dan dilakukan persentase seberapa persenkan mahasiswa dapat menjawab instrumen yang diberikan. Setelah dilakukan persentase, peneliti menginterpretasikan dari hasil jawaban responden dan menarik suatu kesimpulan dari questioner yang dijawab oleh responden. 


\section{HASIL DAN PEMBAHASAN}

Pada penelitian ini didapat hasil data bahwa dari jumlah mahasiswa yang mengisi angket berjumlah 124, sebesar 98,4\% dapat membaca Al-quran menggunakan metode IQRA, dan sisanya menggunakan metode lain. Untuk lebih jelasnya bisa dilihat dari gambar berikut:

\section{Apakah anda dapat membaca al-quran melalui metode IQRA ?}

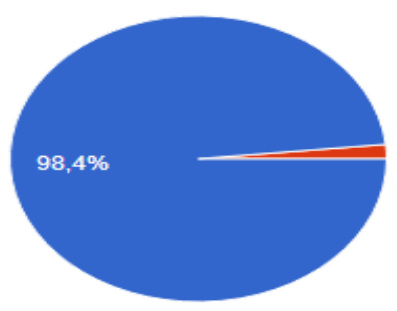

$$
\text { Bisa }
$$

Selain pertanyaan tentang apakah mahasiswa dapat membaca Al-quran dengan metode Iqro, penelitian juga membuat pertanyan tentang usia berapa mahasiswa dapat membaca Alquran dan surat di dalam Al-quran yang sering mahasiswa baca. Dari dua pertanyan tersebut didapat hasil sebagai berikut:

1. Rata-rata mahasiswa PAI dapat membaca Al-quran saat usia 7-10 tahun dengan persentase 43,5\%, sebesar 18,5\% mereka dapat membaca Al-quran saat usia 11-13 tahun, sebesar 14,4 \% saat usia 14-18 tahun mereka baru dapat membaca Al-quran dan sebesar 8,1\% diusia 17 tahun sampai sekarang bisa membaca Al-quran.

2. Surat yang paling sering mahasiswa baca adalah ayat kursi dengan persentase $37,9 \%$ dan kedua yaitu surat yasin.

Untuk lebih jelasnya dapat dilihat pada gambar berikut: 


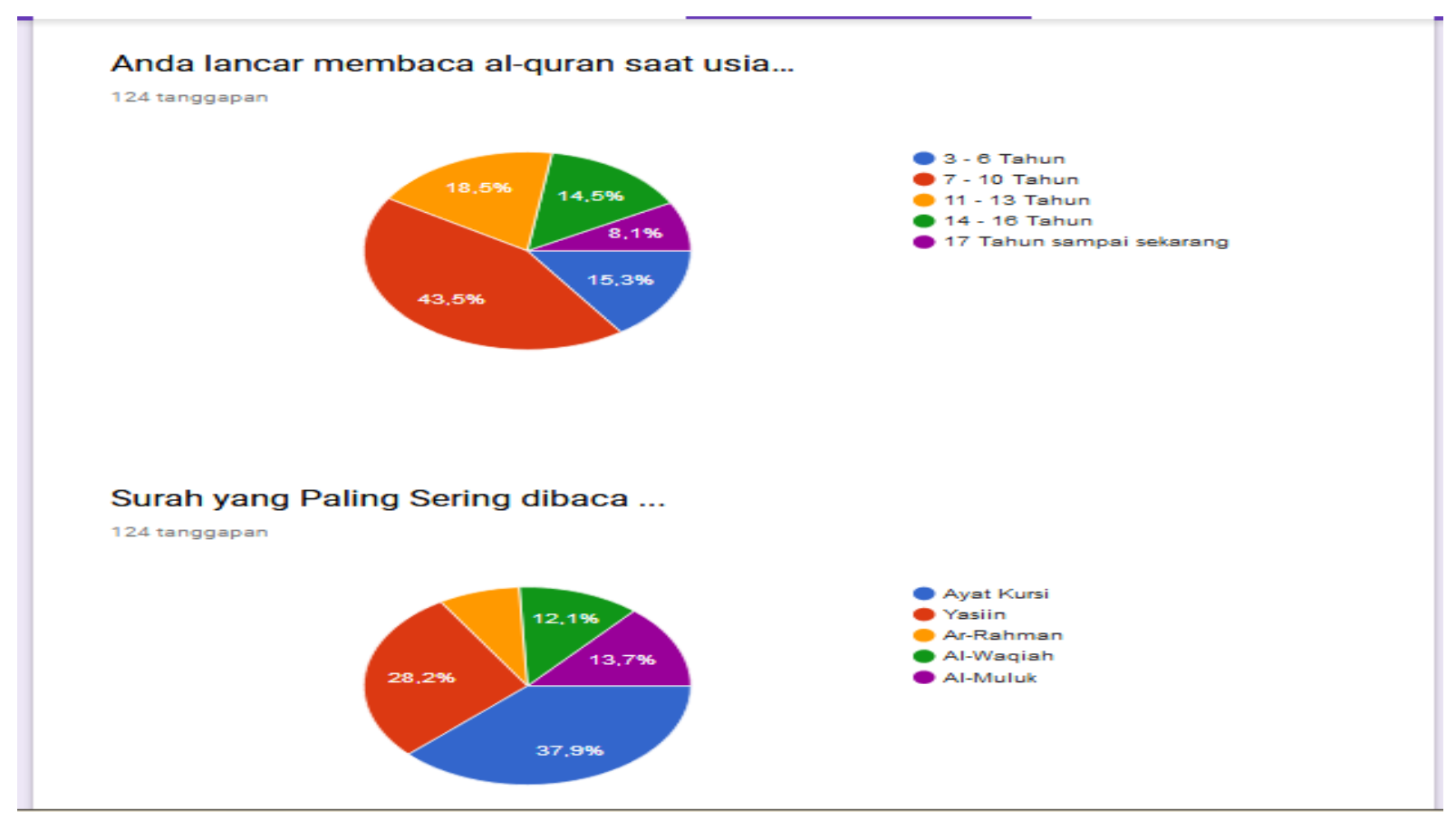

Pertanyaan selanjutnya adalah, peneliti menanyakan apakah mahasiswa PAI UHAMKA mengenal ayat-ayat Muqothoat dan apakah mahasiswa mengetahui istilah fawatihussuwar. Dari dua pertanyan tersebut peneliti mendapatkan hasil sebagai berikut:

1. Mahasiswa yang belum memahami muqothoaat sebesar $66,1 \%$. Sedangkan $33,9 \%$ lainnya sudah mengetahui ayat-ayat muqothoat.

2. Mahasiswa yang belum memahami istilah fawatihussuwar sebesar $71,8 \%$. Sedangkan $28,2 \%$ lainnya sudah mengetahui fawatihussuwar

Untuk lebih jelasnya dapat dilihat dari gambar berikut: 
Apakah anda mengenal ayat-ayat muqothoat.

124 tanggapan

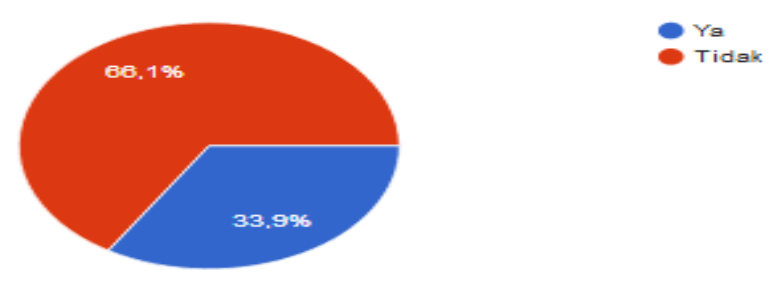

Apakah anda mengetahui istilah fawatihussuwar?

124 tanggapan
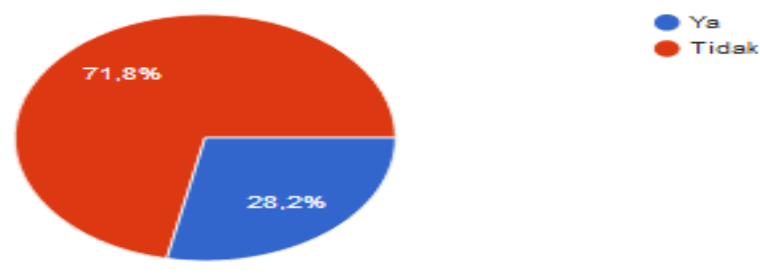

Selanjutnya peneliti membuat pertanyaan yang lebih mendalam tentang pembacaan Alquran. Peneliti memberikan sebuah ayat kemudian memberikan pilihan bacaannya. Dari pertanyaan tersebut didapat hasil sebagai berikut:

1. Pada gambar 1 Sebesar $89,5 \%$ mahasiswa mampu menjawab dengan benar ayat yang diberikan peneliti. Sedangkan 10,5\% mahasiswa masih menjawan salah.

2. Pada gambar 2 Sebesar $97,6 \%$ mahasiswa mampu menjawab ayat yang diberikan peneliti. di samping dengan bacaan yang benar sisanya menjawab salah $2,4 \%$

Untuk lebih jelasnya dapat dilihat dari gambar berikut: 
ayat di samping dibaca ... (الم)

124 tanggapan

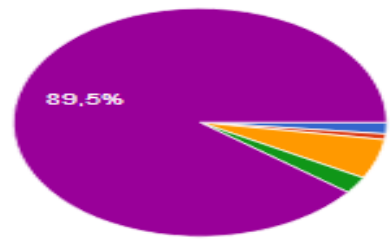

- A la ma

ayat di samping dibaca.. (المصن)

124 tanggapan

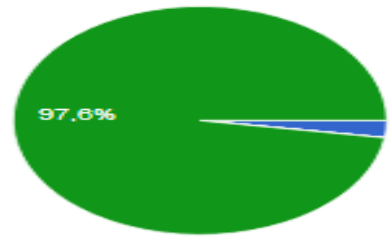

Pertanyaan selanjutnya peneliti masih membuat pertanyaan tentang bacaan huruf. Dari hasil pertanyaan tersebut didapatkan hasil sebagai berikut:

1. Pada gamabr 1 sebesar $95,2 \%$ mahasiswa mampu membaca ayat di samping dengan bacaan yang benar sisanya menjawab salah sebesar $4,8 \%$.

2. Pada gambar 2 sebesar $91,9 \%$ mahasiswa mampu membaca ayat di samping dengan bacaan yang benar sisanya menjawab salah sebesar $8,1 \%$.

Untuk lebih jelasnya dapat dilihat pada gambar berikut: 
ayat di samping dibaca.. (كهي (كصن)

124 tanggapan
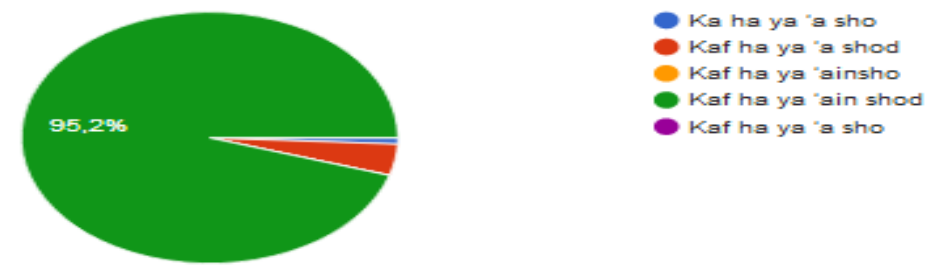

ayat di samping dibaca.. (طسم)

124 tanggapan
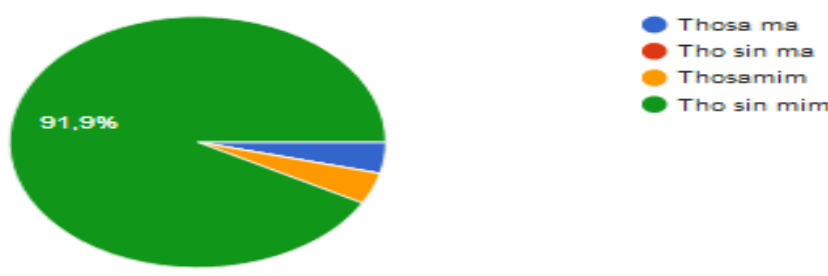

Tho sin mim

\section{KESIMPULAN}

Dari hasil analisis yang dilakukan oleh peneliti dapat ditarik kesimpulan bahwa mahasiswa masih belum mengetahui dan memahami ayat-ayat muqothoat. Selain itu, mahasiswa juga masih belum mengetahui dan memahami fawatihussuwar. Mereka dapat melafalkan ayatayat muqothoat dan fawatihussuwar dengan benar, tetapi mereka masih belum mengetahui dan memahami bahwa beberapa ayat dari angket merupakan ayat-ayat muqothoat dan fawatihussuwar. 


\section{DAFTAR PUSTAKA}

Ali, Atabih. Kontemporer Arab-Indonesia Cet. I; Yogyakarta: Yayasan Ali Maksum Pondok Pesantren Krapyah, 1996.

Hasan, M. Ali dan Rif’at Syauqi Nawawi. Pengantar Ilmu Tafsi. Jakarta: Bulan Bintang, 1988.

Khalil, Moenawar. Al-quran dari Masa ke Masa. Solo: Kenari, 1985.

Mardan. Al-quran: Sebuah Pengantar Memahami Al-quranSecara Utuh. Cet. I; Jakarta: Pustaka MAPAN, 2009.

Al-Suyuti, Jalal al-Din. Al-Itqan fi Ulum Al-Qur'an. Juz I Beirut: Mu'assasat al-Kutub asTsaqafiyah, 1996.

Al-Zarqaniy, 'Abd al-Azim. Manahil al-'Irfan fi 'Ulum Al-Qur'an. Jilid I Beirut:Dar Ihya alTuras al-Arabiy, 1995.

Al-Zarkasyi. Al-Burhan fi Ulum Al-Qur'an. Cet. I; Beirut: t.p., 1988.

Zainun, Muh. Ibnu Jamil. Kaifa Nafham Al-quran diterjemahkan oleh Mashuri dengan judul Pemahaman Al-Qur'an. Cet. I; Bandung: Gema Risalah Press, 1997 